\title{
LETTERATURA DI IMMIGRATI: \\ COMPOSIÇÕES POÉTICAS PUBLICADASA NA \\ IMPRENSA ITALIANA BELO-HORIZONTINA NO \\ INÍCIO DO SÉCULO XX
}

\author{
Letteratura di Immigrati: Composizioni Poetiche \\ Pubblicate nella Stampa Italiana Belo-horizontina \\ nel Primo Novecento
}

\author{
Letteratura di Immigrati: Poetic Compositions \\ Published in the Italian Belo-horizontina Press in the \\ Early $20^{\text {th }}$ century \\ Evandro L.T.P. Cunha* \\ LORENZA LOURENÇO ${ }^{* *}$
}

RESUMO: Em função da construção de Belo Horizonte, iniciada nos últimos anos do século XIX, ocorreu um intenso fluxo de imigrantes de origem italiana para a nova capital do estado. Nesse contexto, uma relevante manifestação sociocultural foi o surgimento de periódicos de imprensa voltados para a própria comunidade imigrante, a fim de que fossem constituídos meios de sociabilidade entre seus membros e, de alguma forma, fosse mantida sua identidade cultural. Vários desses periódicos preservaram-se graças à Coleção Linhares, atualmente mantida pela Universidade Federal de Minas Gerais, a qual contém edições que circularam em Belo Horizonte entre 1895 e 1954. Os principais objetivos deste trabalho são compilar, documentar e brevemente analisar composições poéticas publicadas no que pode ser chamada de imprensa italiana belo-horizontina dos primórdios do século XX. Coletou-se e examinou-se toda a produção poética publicada em edições dos periódicos prevalentemente em língua italiana que

* Universidade Federal de Minas Gerais (UFMG)

evandrocunha@dcc.ufmg.br - (ORCID: 0000-0002-5302-2946)

** Universidade Federal de Minas Gerais (UFMG)

lorenzalourenco@ufmg.br-(ORCID: 0000-0003-0903-4066)

DOI: http://dx.doi.org/10.11606/issn.2238-8281.v0i40p14-34 
constam da Coleção Linhares, dando ênfase àquela produzida por imigrantes em Minas Gerais. Dessa forma, tornamos pública a atividade poética, geralmente amadora, dos italianos que constituíram o estado, contribuindo assim para a divulgação de manifestações literárias de comunidades imigrantes no Brasil.

PALAVRAS-CHAVE: imprensa italiana no Brasil; literatura de imigrantes; poesia italiana.

RIASSUNTO: In funzione della costruzione di Belo Horizonte, iniziata negli ultimi anni dell'Ottocento, vi fu un intenso flusso di immigrati italiani verso la nuova capitale dello stato. In questo contesto, una rilevante manifestazione socioculturale è stato l'emergere di una stampa rivolta alla propria comunità di immigrati, con la finalità di stabilire la socialità tra i suoi membri e, in qualche modo, mantenere la loro identità culturale. Molti di questi giornali e riviste si conservarono grazie alla Coleção Linhares, attualmente gestita dall'Universidade Federal de Minas Gerais, che contiene edizioni che circolarono a Belo Horizonte tra il 1895 e il 1954. Gli obiettivi principali di questo lavoro sono compilare, documentare e brevemente analizzare composizioni poetiche pubblicate in quella che può essere definita come la stampa italiana belo-horizontina dei primi del Novecento. È stata raccolta ed esaminata tutta la produzione poetica pubblicata in edizioni di giornali e riviste prevalentemente in lingua italiana contenuti nella Coleção Linhares, enfatizzando quella prodotta da immigrati italiani in Minas Gerais. In questo modo, rendiamo pubblica l'attività poetica, generalmente amatoriale, degli immigrati italiani nello stato, contribuendo così alla divulgazione di manifestazioni letterarie di comunità di immigrati in Brasile.

PAROLE CHIAVE: stampa italiana in Brasile; letteratura di immigrati; poesia italiana.

ABSTRACT: As a result of the construction of Belo Horizonte, which began in the last years of the 19th century, there was an intense flow of immigrants of Italian origin to the new capital of the state. In this context, a relevant socio-cultural manifestation was the emergence of press periodicals focused on the immigrant community itself, to constitute means of sociability among its members and, somehow, to maintain its cultural identity. Several of these journals were preserved thanks to the Linhares Collection, currently maintained by the Federal University of Minas Gerais, which contains editions that circulated in Belo Horizonte between 1895 and 1954. The main objectives of this work are to compile, document and briefly analyze poetic compositions published in what may be called the Italian belo-horizontine press of the early 20th century. The entire poetic production published in editions of the periodicals, predominantly in Italian, that 


$$
-
$$




\section{Introdução}

A partir dos últimos anos do século XIX, durante o período de construção de Belo Horizonte, a nova capital de Minas Gerais passou a receber muitos trabalhadores estrangeiros, dentre os quais muitos imigrantes italianos. Esse fluxo migratório não cessou após o fim da construção da cidade, quando italianos continuaram a se deslocar para Belo Horizonte, geralmente atendendo ao chamado de parentes e com a intenção de se fixarem permanentemente (FILGUEIRAS, 2011).

A fim de manterem e expressarem sua identidade cultural, os imigrantes italianos criaram escolas, associações e meios para a manifestação de sua própria cultura. Um desses meios foi a publicação de jornais e revistas: muito além de simples veiculadores de notícias, esses periódicos eram uma forma de aproximação entre os imigrantes, permitindo um espaço de interação entre eles (COSTA, 2013). Vários desses jornais e revistas produzidos em Belo Horizonte na primeira metade do século XX foram preservados graças à Coleção Linhares, um rico acervo de periódicos publicados na capital mineira entre os anos de $1895^{1}$ e 1954 . A análise desse material permite que sejam investigados os mais variados aspectos relacionados ao modo de vida dos primeiros habitantes da cidade, inclusive suas predileções artísticas e literárias.

O presente artigo possui como principal objetivo explorar a publicação de composições poéticas nos periódicos voltados para a comunidade italiana contidos na Coleção Linhares, dando especial ênfase àquelas produzidas pelos próprios imigrantes. Torna-se possível, assim, estudar uma das manifestações culturais dos italianos que viviam nas primeiras décadas de Belo Horizonte, contribuindo para a divulgação de sua produção literária.

\section{Metodologia}

Todos os periódicos analisados durante a realização deste trabalho fazem parte da Coleção Linhares, atualmente mantida pela Universidade Federal de Minas Gerais (UFMG). A Coleção Linhares pode ser consultada fisicamente na Biblioteca Central da UFMG e, na data de publicação deste artigo, parte dela já estava disponibilizada para acesso online² (MOREIRA DOS SANTOS; SILVA DOS SANTOS; DOS SANTOS, 2011). Essa coleção é um raro e extenso acervo constituído por periódicos (jornais, revistas, panfletos etc.) que circularam em Belo Horizonte entre 1895 e 1954, os quais foram coletados, organizados e catalogados pelo colecionador Joaquim Nabuco Linhares. Além de servirem como um precioso retrato dos cinquenta primeiros anos da capital mineira, os periódicos que compõem a coleção têm sido objeto de diversos estudos acadêmicos interessados na investigação de questões histórico-culturais (e.g. LOTT, 2009; DOS PASSOS, 2014), linguísticas (e.g. CUNHA, no prelo) e hábitos de vida da população belo-horizontina (e.g. SOUZA NETO; SILVA, 2009), para citar alguns.

Em 1995, publicou-se sob o título Itinerário da imprensa de Belo Horizonte: 1895-1954

1 Isto é, ainda antes da fundação da cidade, ocorrida em 1897.

2 No endereço http://www.linhares.eci.ufmg.br 
o catálogo da coleção de Joaquim Nabuco Linhares (LINHARES, 1995). Em sua dissertação sobre imigrantes italianos em Belo Horizonte na primeira metade do século XX, Cavalieri (2011) informa ter identificado, dentre os 839 títulos catalogados, edições dos seguintes treze periódicos voltados para a comunidade de imigrantes italianos na cidade: Un Fiore (19001901), Il Martello (1902-1902), La Voce del Cuore (1902-1902), L'Eco del Popolo (1905-1905), Roma (1910-?), Fieramosca (1916-1921), Araldo Italiano (1923-?), La Voce Coloniale (1924?), La Squilla (1926-?), Voce Latina (1926-1927), Italia Nuova (1928-1929), Italia (1936-?) e L'Arrotino Coloniale (1937-?) ${ }^{3}$. Desses, cinco já estavam, quando da elaboração deste artigo, disponíveis para acesso online: Araldo Italiano, Fieramosca, L'Arrotino Coloniale, L'Eco del Popolo e Un Fiore; o restante foi consultado diretamente na Biblioteca Central da UFMG. Verificou-se, entretanto, que as edições do periódico Voce Latina, apesar de catalogadas, não estavam disponíveis nem na coleção física, nem na coleção digital: acredita-se que tenham sido perdidas. Convém esclarecer ainda que o grau de uso das línguas italiana e portuguesa varia entre os periódicos consultados: alguns deles foram editados exclusivamente em língua italiana, enquanto outros chegam a contar com seções inteiras em língua portuguesa.

Neste trabalho, foram examinadas todas as edições dos periódicos italianos mencionados acima em busca de composições poéticas neles publicadas. Para a definição de composição poética, apesar de se concordar com a concepção de que a distinção entre poesia e prosa não deve levar em conta apenas o aspecto exterior e formal do texto (cf. TAVARES, 1969), considerou-se, por simplicidade, qualquer composição escrita em verso, ao passo que composições publicadas em prosa ou em outras formas não foram contempladas. Na próxima seção, apresentam-se as composições que, no acervo consultado, atendem a esse critério.

\section{Composições poéticas presentes no acervo consultado}

Foi possível distinguir as composições poéticas encontradas nos periódicos explorados em duas categorias: (a) reproduções de poemas compostos por autores conhecidos da literatura e sem relação direta com a colônia italiana belo-horizontina; (b) poemas pouco ou nada conhecidos do grande público, em muitos casos produzidos pelos próprios membros da comunidade italiana em Minas Gerais. Para a delimitação entre essas categorias, efetuou-se pesquisa bibliográfica e virtual: os poemas cujos versos não foram encontrados a partir dessa pesquisa foram inseridos na categoria (b). O Quadro 1 lista, a título de informação, os poemas (ou trechos) escritos por autores reconhecidos da literatura italiana reproduzidos nos periódicos consultados - isto é, os poemas italianos que compõem a categoria (a).

3 As datas referem-se aos anos de início e interrupção (quando informado) de publicação dos periódicos, conforme o índice cronológico disponível em Linhares (1995, p. 542-565). 
Quadro 1: Composições poéticas escritas por autores da literatura italiana reproduzidas nos jornais e revistas consultados. Os poemas estão listados em ordem cronológica de publicação nos periódicos.

\begin{tabular}{|c|c|c|c|}
\hline Periódico & $\begin{array}{l}\text { Data e } \\
\text { página }\end{array}$ & Poema & Autor \\
\hline Un Fiore & $\begin{array}{c}\text { 18/11/1900 } \\
\text { f.1 }\end{array}$ & $\begin{array}{l}\text { Versos } 13-15 \text { do canto } \mathrm{V} \text { do } \\
\text { Purgatorio. O trecho está publi- } \\
\text { cado no jornal sob o título } U n \\
\text { fiore. }\end{array}$ & $\begin{array}{l}\text { Dante Alighieri }{ }^{4} \text { (o nome } \\
\text { do autor não é menciona- } \\
\text { do na publicação) }\end{array}$ \\
\hline $\begin{array}{c}\text { L'Eco del } \\
\text { Popolo }\end{array}$ & $\begin{array}{c}28 / 05 / 1905 \\
\text { f. } 2\end{array}$ & $\begin{array}{l}\text { Io son l'amore (Aprite la fine- } \\
\text { stra, o vago fiore). Versos da } \\
\text { canção Io son l'amore, de } \\
\text { Francesco Paolo Tosti. Há uma } \\
\text { alteração na ordem dos versos. }\end{array}$ & $\begin{array}{l}\text { Francesco Cimmino (o } \\
\text { nome do autor é indica- } \\
\text { do apenas pelas iniciais } \\
\text { F.C.) }\end{array}$ \\
\hline Roma & $\begin{array}{l}\text { 20/09/1910 } \\
\text { f.2 }\end{array}$ & $\begin{array}{l}\text { Versos } 49-52 \text { do poema Per } \\
\text { il quinto anniversario della } \\
\text { Battaglia di Mentana, publi- } \\
\text { cado no Giambi ed epodi. } \\
\text { Giuseppe Mazzini, soneto publi- } \\
\text { cado no Giambi ed epodi. }\end{array}$ & $\begin{array}{l}\text { Giosuè Carducci }^{5} \\
\text { Giosuè Carducci }\end{array}$ \\
\hline
\end{tabular}

4 Dante Alighieri (1265-1321): poeta, escritor e político florentino, autor da Divina Commedia e um dos grandes nomes da história da literatura universal.

5 Giosuè Carducci (1835-1907): poeta, escritor e crítico literário toscano, agraciado com o Prêmio Nobel de Literatura em 1906. 


\begin{tabular}{|c|c|c|c|}
\hline Fieramosca & $\begin{array}{c}25 / 03 / 1916, \\
f .1 \\
\text { 25/03/1916, } \\
\text { f.1 } \\
\\
\text { 29/03/1916, } \\
\text { f.1 } \\
\\
01 / 04 / 1916, \\
\text { f.1 } \\
\\
14 / 01 / 1917, \\
\text { f.2 }\end{array}$ & $\begin{array}{l}\text { Três versos de Poesie naziona- } \\
\text { li. Estão inseridos em um texto } \\
\text { maior, escrito em prosa, intitu- } \\
\text { lado Psiche. } \\
\text { Quatro versos de La marcia di } \\
\text { Leonida. Estão inseridos em um } \\
\text { texto maior, em prosa, intitula- } \\
\text { do Psiche. } \\
\text { Dois versos da estrofe } 62 \text { do } \\
\text { primeiro canto da Gerusalemme } \\
\text { liberata. Estão inseridos no } \\
\text { texto em prosa Psiche. } \\
\text { Quatro versos de Carlo } \\
\text { Pisacane e la spedizione di } \\
\text { Sapri. Estão inseridos no texto } \\
\text { em prosa Bonaventura Zumbini. } \\
\text { Neri e lo strolago, soneto em } \\
\text { dialeto pisano. }\end{array}$ & $\begin{array}{l}\text { Giovanni B. Niccolini } \\
\text { (o nome do autor não é } \\
\text { mencionado no jornal) } \\
\text { Felice Cavallotti }{ }^{6} \text { (o } \\
\text { nome do autor não é } \\
\text { mencionado no jornal) } \\
\text { Torquato Tasso }{ }^{8} \text { (o nome } \\
\text { do autor não é menciona- } \\
\text { do no jornal) } \\
\text { Eliodoro Lombardi }{ }^{9} \text { (o } \\
\text { nome do autor não é } \\
\text { mencionado no jornal) } \\
\text { Neri Tanfucio }^{10}\end{array}$ \\
\hline
\end{tabular}

$6 \quad$ Giovanni Battista Niccolini (1782-1861): dramaturgo e poeta toscano.

$7 \quad$ Felice Cavallotti (1842-1898): político, poeta, dramaturgo e jornalista milanês.

8 Torquato Tasso (1544-1595): poeta, escritor, dramaturgo e filósofo sorrentino, conhecido principalmente pelo poema épico Gerusalemme liberata.

$9 \quad$ Eliodoro Lombardi (1834-1894): poeta e escritor siciliano.

10 Neri Tanfucio, pseudônimo e anagrama de Renato Fucini (1843-1921): poeta e escritor toscano. 


\begin{tabular}{|c|c|c|c|}
\hline $\begin{array}{l}\text { Araldo } \\
\text { Italiano }\end{array}$ & $\begin{array}{c}\text { 22/07/1923, } \\
\text { f.1 } \\
02 / 09 / 1923, \\
\text { f.1 } \\
\\
\text { 20/09/1923, } \\
\text { f.1 } \\
\text { 31/10/1923, } \\
\text { f.1 } \\
\text { 25/11/1923, } \\
\text { f.1 } \\
\\
18 / 12 / 1923, \\
\text { f.1 } \\
\text { 18/12/1923, } \\
\text { f.1 }\end{array}$ & $\begin{array}{l}\text { I bimbi. É, na verdade, apenas } \\
\text { um dos sonetos do autor com } \\
\text { esse título. } \\
\text { Trecho da ópera Attilio Regolo. } \\
\text { Está publicado no jornal sob o } \\
\text { título Dall'Attilio Regolo. } \\
\text { Il } 20 \text { Settembre } 1870 \text {, soneto em } \\
\text { referência à Tomada de Roma. } \\
\text { A mia madre. Há pelo menos } \\
\text { um outro poema do autor com } \\
\text { esse título. } \\
\text { Soneto LIV do Postuma: canzo- } \\
\text { niere di Lorenzo Stecchetti. Está } \\
\text { publicado no jornal sob o título } \\
\text { Dal Postuma. } \\
\text { Soneto XXXIII. Está publica- } \\
\text { do no jornal na seção "I grandi } \\
\text { italiani". } \\
\text { La morta. Poema } 157 \text { de } \\
\text { Poemetti Lirici. A quarta (e } \\
\text { última) estrofe não foi publica- } \\
\text { da no jornal. }\end{array}$ & $\begin{array}{l}\text { Edmondo de Amicis }{ }^{11} \\
\text { Pietro Metastasio }{ }^{12} \\
\text { Edmondo de Amicis } \\
\text { Edmondo de Amicis } \\
\text { Lorenzo Stecchetti }{ }^{13} \text { (o } \\
\text { sobrenome está grafado } \\
\text { sem o } i \text { : Stecchett }) \\
\text { Galeazzo di Tarsia }{ }^{14} \\
\text { Giovanni Bertacchi }{ }^{15}\end{array}$ \\
\hline $\begin{array}{l}\text { La Voce } \\
\text { Coloniale }\end{array}$ & $\begin{array}{c}10 / 07 / 1924 \\
\text { f. } 3\end{array}$ & $\begin{array}{l}\text { Soneto do Le rime di Lorenzo } \\
\text { Stecchetti, publicado no jornal } \\
\text { sob o título Visioni di morte. }\end{array}$ & $\begin{array}{l}\text { Olindo Guerrini }{ }^{16} \text { (o } \\
\text { pseudônimo Lorenzo } \\
\text { Stecchetti não é mencio- } \\
\text { nado no jornal) }\end{array}$ \\
\hline
\end{tabular}

Mais relevantes para este estudo, porém, são as composições produzidas por membros da comunidade de imigrantes italianos em Minas Gerais, pois testemunham a atividade literária, em muitos casos amadora, dos próprios integrantes da colônia. Dentre essas composições, há aquelas cujos autores estão explicitamente identificados, permitindo assim seu reconhecimento individual. Há também poemas assinados por pseudônimos e, ainda, poemas sem qualquer tipo de assinatura, impedindo (ou, no mínimo, dificultando) a identificação de seus autores. O Quadro 2 inclui todas as composições em língua italiana encontradas nos periódicos e não citadas no Quadro 1 - isto é, inclui aquelas possivelmente ou, em alguns casos, certamente escritas por membros da comunidade italiana em Minas Gerais.

11 Edmondo de Amicis (1846-1908): escritor e jornalista de origem lígure, conhecido sobretudo pelo romance infantojuvenil Cuore.

12 Pietro Metastasio (1698-1792): poeta, escritor e libretista de origem romana.

13 Lorenzo Stecchetti, pseudônimo de Olindo Guerrini (1845-1916): poeta e escritor emiliano-romanhol, expoente da literatura positivista.

14 Galeazzo di Tarsia (1520?-1553): poeta napolitano.

15 Giovanni Bertacchi (1869-1942): poeta, acadêmico e crítico literário lombardo.

16 Sobre Olindo Guerrini (1845-1916), ver nota 16. 
Quadro 2: Composições poéticas possivelmente ou, em alguns casos, certamente escritas por membros da comunidade italiana em Minas Gerais. Os poemas são listados em ordem cronológica de publicação nos periódicos.

\begin{tabular}{|c|c|c|c|}
\hline Periódico & Data e página & Poema & Autor \\
\hline Un Fiore & 18/11/1900, f.2 & Ai nostri lettori & [não consta] \\
\hline Il Martello & 27/07/1902, f.4 & Ricordando & Niente! (pseudônimo) \\
\hline $\begin{array}{c}\text { L'Eco del } \\
\text { Popolo }\end{array}$ & $\begin{array}{l}\text { 28/05/1905, f.3 } \\
04 / 06 / 1905, \text { f.3 } \\
\\
\text { 11/06/1905, f.2 } \\
11 / 06 / 1905, \text { f.3 } \\
20 / 06 / 1905, \text { f.3 }\end{array}$ & $\begin{array}{l}\text { Vino Raboso } \\
\text { Vino Raboso (igual ao de } \\
28 / 05 / 1905 \text { ) } \\
\text { L'uncinetto } \\
\text { Vino Raboso (igual ao de } \\
28 / 05 / 1905 \text { ) } \\
\text { Vino Raboso (igual ao de } \\
28 / 05 / 1905 \text { ) }\end{array}$ & $\begin{array}{l}\text { Biondino (pseudônimo?) } \\
\text { Biondino (pseudônimo?) } \\
\text { [não consta] } \\
\text { Biondino (pseudônimo?) } \\
\text { Biondino (pseudônimo?) }\end{array}$ \\
\hline $\begin{array}{l}\text { Araldo } \\
\text { Italiano }\end{array}$ & $\begin{array}{l}\text { 31/07/1923, f.1 } \\
\text { 18/08/1923, f.1 } \\
\text { 02/09/1923, f.1 } \\
\text { 20/10/1923, f.1 } \\
\text { 25/11/1923, f.1 } \\
\text { 18/12/1923, f.1 }\end{array}$ & $\begin{array}{l}\text { Tramonto } \\
\text { Trittico di Aprile } \\
\text { Perché affrettarsi? } \\
\text { La cicogna, tradução de } \\
\text { A cegonha, de Aníbal } \\
\text { Teófilo. } \\
\text { Stornellata } \\
\text { Stornellata (diferente da } \\
\text { anterior) }\end{array}$ & $\begin{array}{l}\text { A. Salemi (provavelmente um } \\
\text { pseudônimo) } \\
\text { Aulo Postumio (talvez um } \\
\text { pseudônimo) } \\
\text { Pietro Pezzuti } \\
\text { Tolentino Miraglia } \\
\text { Pietro Pezzuti (o sobrenome } \\
\text { do autor está grafado sem o } i \text { : } \\
\text { Pezzut) } \\
\text { Pietro Pezzuti }\end{array}$ \\
\hline La Squilla & $\begin{array}{l}07 / 11 / 1926, \text { f. } 2 \\
24 / 07 / 1927, \text { f.2 } \\
\\
24 / 07 / 1927, \text { f. } 3 \\
24 / 07 / 1927, \text { f.3 }\end{array}$ & $\begin{array}{l}\text { I cercatori d'oro } \\
\text { L'Inno di....Frola } \\
\text { Le ultime cartuccie } \\
\text { Il solito }\end{array}$ & $\begin{array}{l}\text { Giulio Boncompagni } \\
\text { Uno che frolla nel manico } \\
\text { (pseudônimo) } \\
\text { [não consta] } \\
\text { [não consta] }\end{array}$ \\
\hline
\end{tabular}


Nos parágrafos seguintes, são apresentadas informações adicionais sobre os poemas e os autores mencionados no Quadro 2. Na maioria dos casos, estão reproduzidos recortes dos periódicos e, quando esses recortes são de difícil leitura, incluímos transcrições nossas, sempre respeitando grafia, acentuação e pontuação originais - inclusive eventuais erros.

"Ai nostri lettori" é um pequeno poema de duas estrofes publicado no primeiro número do primeiro periódico italiano de Belo Horizonte ${ }^{17}$ : a edição do Un Fiore de 18/11/1900. A temática é justamente o nascimento de uma vida (metaforicamente, do próprio periódico). Não consta o nome do autor, mas um possível candidato é Giulio Boncompagni, diretor do Un Fiore (de acordo com Linhares (1995)) e autor de um poema publicado anos depois (em 1926) no jornal La Squilla.

\begin{tabular}{|c|c|}
\hline 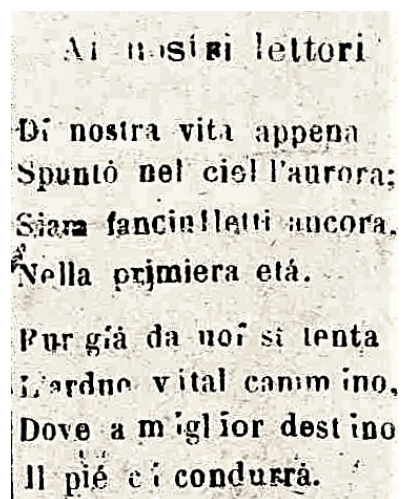 & $\begin{array}{l}\quad \text { Ai nostri lettori } \\
\text { Di nostra vita appena } \\
\text { Spuntò nel ciel l'aurora; } \\
\text { Siam fanciulletti ancora, } \\
\text { Nella primiera età. } \\
\text { Pur già da noi si senta } \\
\text { L'arduo vital cammino, } \\
\text { Dove a miglior destino } \\
\text { Il pié ci condurrà. }\end{array}$ \\
\hline
\end{tabular}

Sobre o poema lírico "Ricordando", publicado no Il Martello de 27/07/1902 e assinado pelo pseudônimo "Niente!", pouco temos a informar. Ao menos três razões nos fazem acreditar que não se trata de poema reproduzido de alguma outra fonte: (a) seus versos não foram encontrados em nossa pesquisa bibliográfica e virtual; (b) consta a possível data de produção do texto (1-1-1901, diferente da data de publicação do jornal), informação raramente disponível; (c) o jornal não apenas não informou o nome do autor, mas ainda teve a preocupação de inserir um pseudônimo. Novamente, Giulio Boncompagni é um possível candidato para sua autoria, tendo em vista que foi proprietário e diretor do Il Martello.

17 Mais do que isso: Linhares (1995, p.77) informa que "Un Fiore foi o primeiro jornal de Belo Horizonte a empregar idioma estranho ao nosso". 


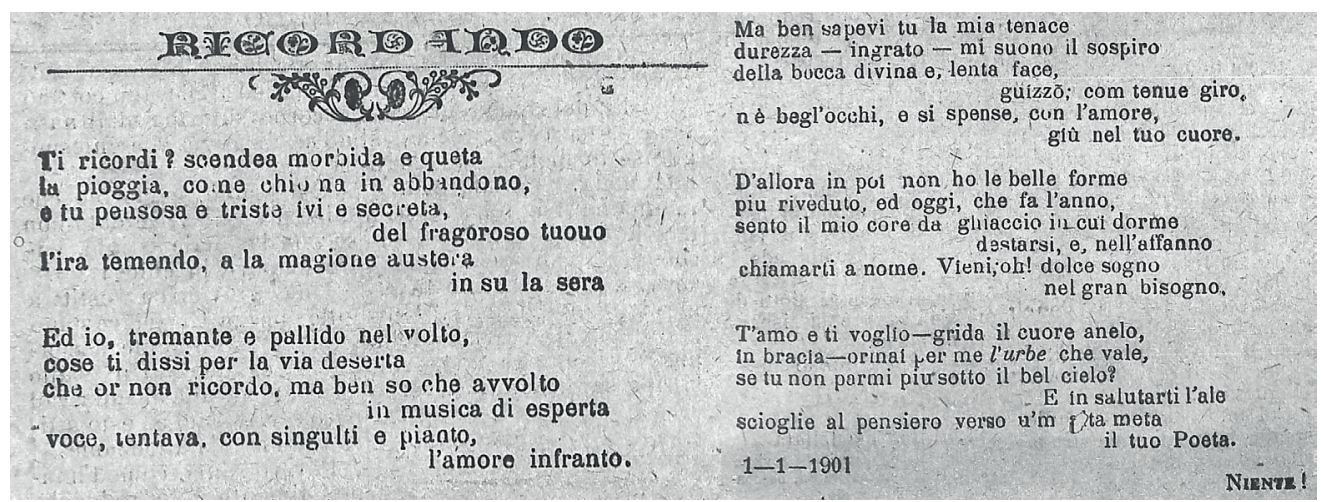

Interessante caso de um poema publicitário, "Vino Raboso" é a propaganda de um vinho à venda "[n]ella Rua Rio de Janeiro" (verso 4), "in casa <<Aita $>>$ " (verso 26). Foi publicado nas quatro edições do jornal L'Eco del Popolo disponíveis na Coleção Linhares, sempre na terceira página, inteiramente dedicada a anúncios.

\section{VINO RABOSO}

Corri, corri lettore amoroso, E vedrai se dico il vero ; Comprâ sempre il vin Raboso. Nella Rua Rio de Janeiro.

Questo vino : Vin Raboso, Si puó dire il re dei vini ;

Dolce, buono, appettitoso ;

E da berlo a centellini.

Questo $e$ il vin di Conegliano Questo ê il vino di Raboso, Si puo dire forte e piano -Piase al vecio, piase al toso.

Ed il Papa, Papa Pio,

Se lo tiene sempre accanto, Esclamando : Buon, perdio !... Ripetendo ad ogni tanto :

-Questo e il vin del suol notio. -Questo vino é proprio il mio !
Ma l'Amaro Montenegro,

Nou $\mathrm{mi}$ fa piú stare allegro.

Pure, pure il Fernet Branca,

Anche quelle ormai mi stanca.

\section{-Viva, yiva il vin Raboso}

-Dolce, buono, appetitoso!

Questo nettare divino

Lo si trova in casa *Aita

$E$ al confronto d'ogni vino

E sol quel che dá la vita.

- Non c'é proprio che vedere,

-E un gran vin miracoloso,

- Sono tutti d'un parere

- Nel gustare il vin Raboso. 
O autor de "Vino Raboso", Biondino (talvez um pseudônimo), assina também um texto literário em prosa intitulado "Scorci e profili" na edição de 04/06/1905, f.2, no qual menciona pontos importantes da cidade, como a "piazza della Libertá" e a "rua Bahia". Ainda que não se encaixe nos critérios adotados para a nossa seleção de composições poéticas, "Scorci e profili" está reproduzido abaixo em função de sua singularidade e relevância para Belo Horizonte.

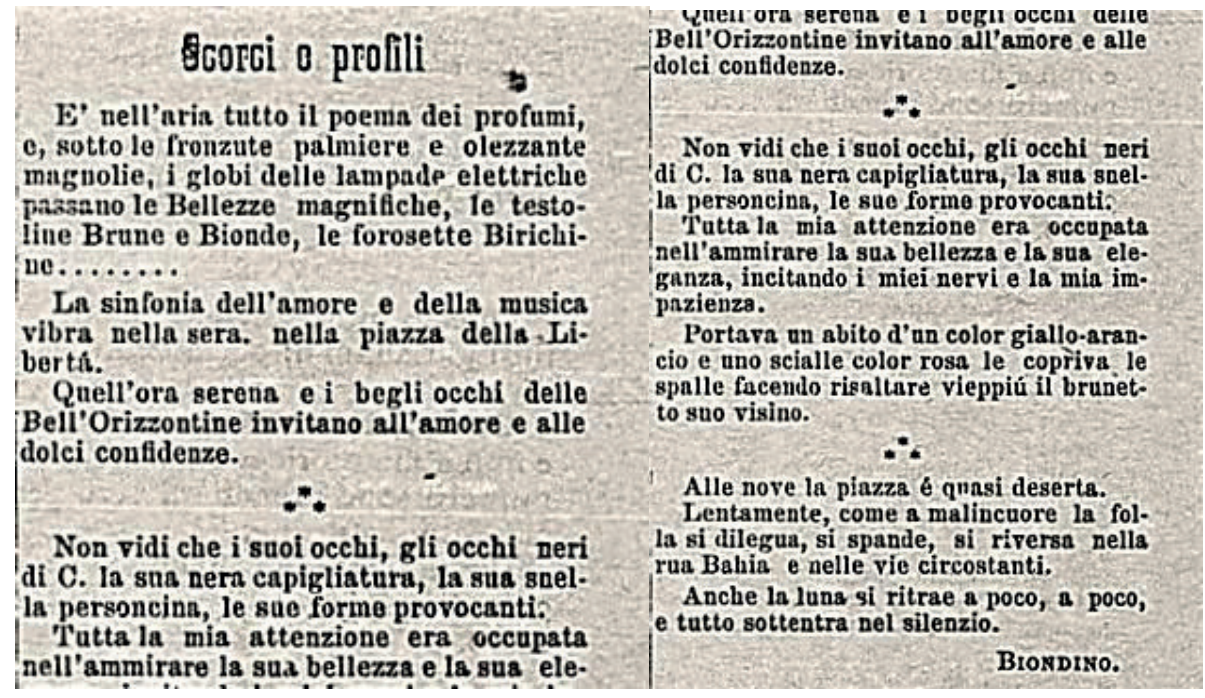

Sobre alguns poemas, é possível apenas tecer conjecturas. É o caso de "L'uncinetto", publicado no L'Eco del Popolo de 11/06/1905, que aparece próximo a um tex to de uma seção voltada para trabalhos femininos ("Lavori feminili" (sic)) sobre crochê ("uncinetto" significa "agulha de crochê"). Não há nenhuma menção ao seu autor e as duas estrofes que compõem o poema se assemelham, por sua simplicidade, a versos populares infantis. Apesar disso, em nossa pesquisa bibliográfica e virtual não foi encontrada nenhuma referência a esses versos: não sabemos, portanto, se foram escritos para o próprio jornal ou se foram reproduzidos a partir de alguma fonte (escrita ou oral) à qual não tivemos acesso. 


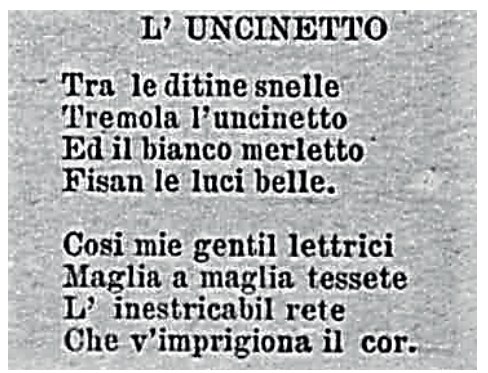

O Araldo Italiano também publicou dois poemas sobre os quais não conseguimos nenhuma informação. Na edição de 31/07/1923 está publicado "Tramonto", assinado por A. Salemi, um singelo poema descrevendo um pôr do sol ("tramonto"). Em nossa pesquisa bibliográfica e virtual, não foi encontrada nenhuma composição similar a essa e nem mesmo nenhuma referência a algum escritor chamado A. Salemi. O nome Salemi, porém, refere-se a uma cidade na Sicília. Supõe-se que A. Salemi seja, então, um pseudônimo para que, em união com o título do poema, possa formar-se a frase "tramonto a Salemi” ("pôr do sol em Salemi"). 


\section{TRAMONTO}

\begin{tabular}{|c|c|}
\hline 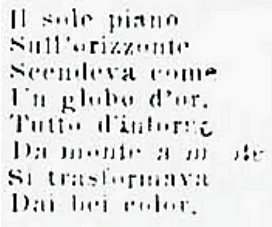 & 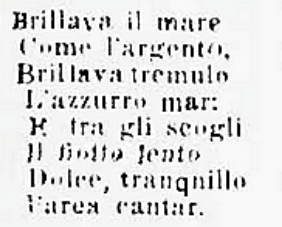 \\
\hline 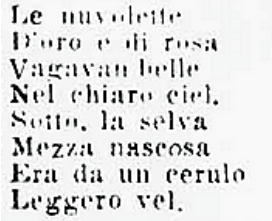 & 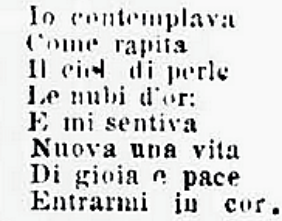 \\
\hline \multicolumn{2}{|c|}{ 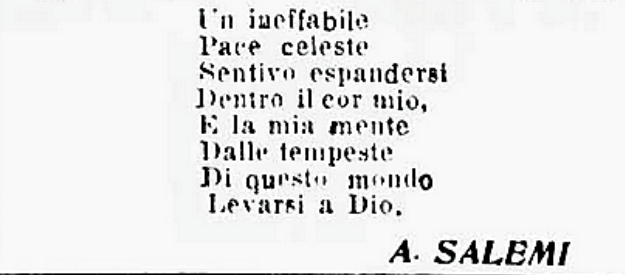 } \\
\hline
\end{tabular}

\begin{tabular}{|c|c|}
\hline Il sole piano & Brillava il mare \\
\hline Sull'orizzonte & Come l'argento, \\
\hline Scendeva come & Brillava tremulo \\
\hline Un globo d'or. & L'azzurro mar: \\
\hline Tutto d'intorno & E tra gli scogli \\
\hline Da monte [?] a monte & Il fiotto lento \\
\hline & Dolce, tranquillo \\
\hline Si trasformava & Parea cantar. \\
\hline
\end{tabular}

Dal bel color.

\section{Le nuvolette \\ D'oro e di rosa \\ Vagavan belle \\ Nel chiaro ciel. \\ Sotto, la selva \\ Mezza nascosa \\ Era da un cerulo \\ Leggero vel.}

\section{Io contemplava \\ Come rapita \\ Il ciel di perle \\ Le nubi d'or: \\ E mi sentiva \\ Nuova una vita \\ Di gioia e pace \\ Entrarmi in cor.}

Un ineffabile
Pace celeste
Sentivo espandersi
Dentro il cor mio,
E la mia mente
Dalle tempeste
Di questo mondo
Levarsi a Dio.

A. SALEMI

O outro caso é o do poema intitulado "Trittico di Aprile", publicado na edição do Araldo Italiano de 18/08/1923. O poema está assinado por Aulo Postumio, remetendo a diversos integrantes da gens romana Postumius que tinham como prenome Aulus - sendo talvez o mais conhecido deles o cônsul Aulus Postumius Albinus. Como em nossa pesquisa bibliográfica e virtual os versos desses poemas não foram identificados, além de não ter sido encontrado nenhum poeta com o nome Aulo Postumio, conjectura-se que, neste caso, Aulo Postumio seja um pseudônimo. Por restrição de espaço, não foi possível reproduzir o Trittico di Aprile neste artigo, pois é uma composição mais longa; no entanto, ele pode ser acessado na página da Coleção Linhares Digital ${ }^{18}$.

18 O endereço para acessar a primeira página do Araldo Italiano do dia 18/08/1923, que contém o Trittico di Aprile, é http://www.linhares.eci.ufmg.br/dados20/0016/1923/001619230818001.jpg (acesso em agosto de 2019). 
Diversas publicações do Araldo Italiano são assinadas pelo médico Pietro Pezzuti (18951960), italiano que se mudou para o Brasil após a Primeira Guerra Mundial, fixando-se em Araxá (ALMEIDA, 2019). Além dos três poemas reproduzidos abaixo, Pezzuti assina outros artigos, como na edição de 20/09/1923, f.1 ("Saluto italico all'italico Araldo") e na edição de 20/10/1923, f.1 ("Decalogo più uno"). Os três poemas de Pietro Pezzuti encontrados são "Perché affrettarsi?" ("Por que se apressar?") e dois "Stornellata" - termo que vem de stornello, "breve canto popolare tipico dell'Italia centrale, d'argomento amoroso o satirico" 19 . Em ambos "Stornellata" consta a informação da cidade mineira onde foram escritos: Araxá.

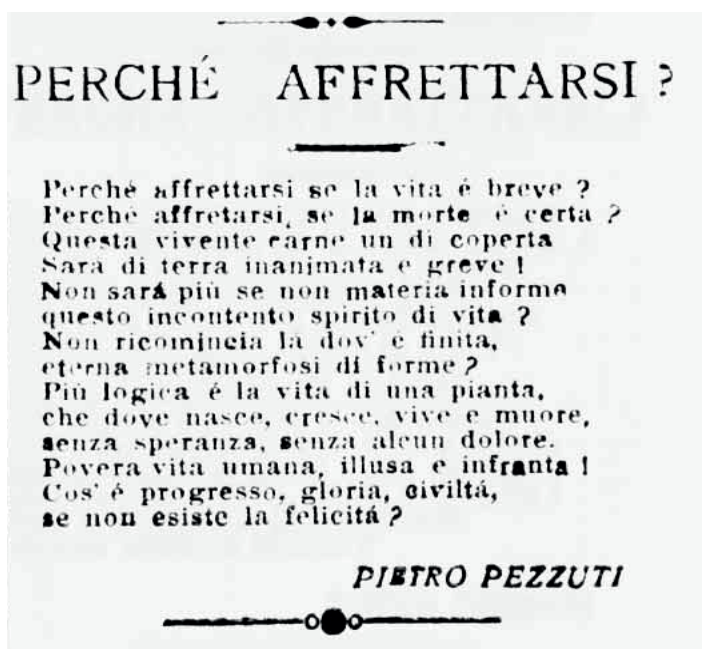

\section{PERCHÉ AFFRETTARSI?}

Perché affrettarsi se la vita è breve ?

Perché affretarsi, se la morte è certa ?

Questa vivente carne un di coperta

Sará di terra inanimata e greve !

Non sará piú se non materia informe questo incontento spirito di vita ? Non ricomincia lá dov' é finita, eterna metamorfosi di forme?

Piú logica é la vita di una pianta che dove nasce, cresce, vive e muore, senza speranza, senza alcun dolore. Povera vita umana, illusa e infranta ! Cos' é progresso, gloria, civiltá, se non esiste la felicitá ?

PIETRO PEZZUTI 

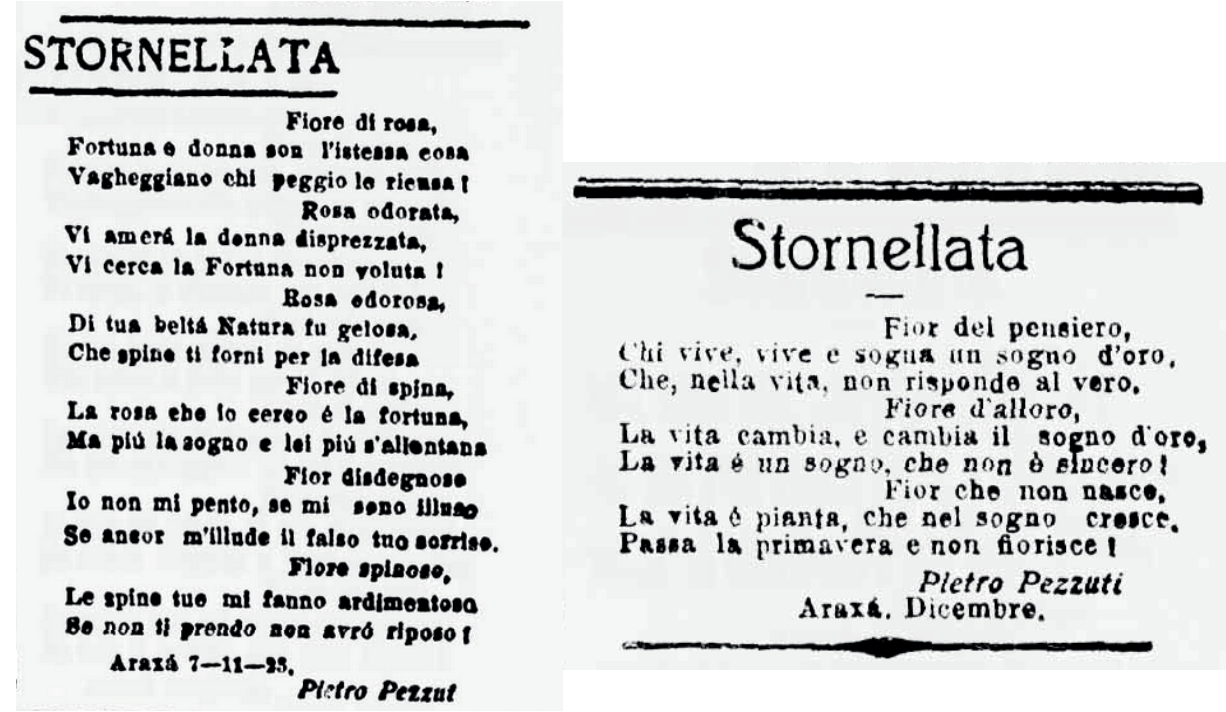

"A cegonha" é um dos mais conhecidos sonetos do poeta brasileiro Aníbal Teófilo (18731915). Tolentino Miraglia (1890-1958) - médico, poeta e professor (DE LUCA, 2008), além de diretor do Araldo Italiano - foi o responsável por esta tradução para a língua italiana. É possível encontrar uma outra versão, com algumas modificações, publicada na coletânea Piccola antologia poetica brasiliana, que contém diversas traduções de poemas brasileiros realizadas por Tolentino Miraglia (MIRAGLIA, 1955). A título de curiosidade, Miraglia é também o autor da letra do Hino ao Palestra Itália de Belo Horizonte. 


\section{La Cicogina \\ (Annibal Theophilo)}

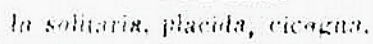

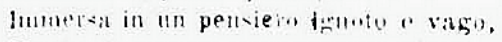

Minem tramonta, sprat azzurro lago,

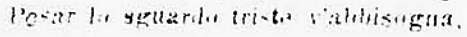

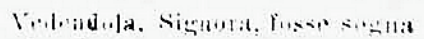

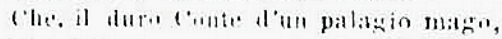

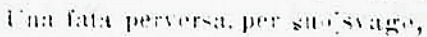

Mnto nellerudiuna ehre trasenana.

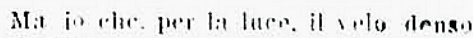

Dell Esore " nun Fiser, diradamil,

Tento teflacemente il huro aceessu:

Vedenstuia milarsi in arepua. pense

Vedere il Juhinir Umano meditamdo

Suliangrustia infinita lli se stesto. $\quad$,

TOLFN'INO MIRACIIIA

\section{La Cicogna}

(Annibal Theophilo)

La solitaria, placida, cicogna,

Immersa in un pensiero ignoto e vago, Mentre tramonta, sopra azzurro lago, Posar lo sguardo triste v'abbisogna.

Vedendola, Signora, forse sogna

Che, il duro Conte d'un palagio mago,

Una fata perversa, per suo svago,

Mutò nell'erodiona che trasogna.

Ma io che, per la luce, il velo denso

Dell'Essere o non Esser, diradando,

Tento tenacemente il duro accesso:

Vedendola mirarsi in acque, penso

Vedere il Dubbio Umano meditando

Sull'angustia infinita di sè stesso.

TOLENTINO MIRAGLIA

Giulio Boncompagni, citado anteriormente, foi proprietário também do jornal de orientação fascista La Squilla, periódico no qual foi publicado seu curioso poema "I cercatori d'oro". A trajetória de Boncompagni, que também atuou no Il Martello, no Italia Nuova, no La Voce del Cuore e no Un Fiore, evidencia o que, de acordo com Cavalieri (2011), era um acontecimento comum da época: o surgimento de jornais com poucas edições e logo em seguida a criação de outros com os mesmos proprietários e diretores. Neste poema, Boncompagni narra a aventura de "quattro soci" (verso 1) que vieram a Minas Gerais com o interesse de enriquecer "non coi frutti del lavoro" (verso 2), mas com a exploração do ouro. O negócio não deu certo, motivo pelo qual "lasciaron tutto e chiusero bottega" (verso 34), despedindo-se da cidade de Mariana e dirigindo-se, então, a Belo Horizonte. Seria "I cercatori d'oro" baseado na história real de algum membro da colônia italiana belo-horizontina? 


\section{I cercatori d'oro}

Si miser quattro soci un dí in mente d'arricchir, non coi frutti del lavoro, ma scoprendo in remoto continente, di là dai monti, una míniera d'oro. Partiron colle scarpe senza tacchi,

e gran copia di piccolini sacchi.

Giunti a Marianna, in piccola casetta, formaro il gran consiglio, a un tavolino; ma l'aria del mattin, viva e freschetta

lor suggerí l'idea di uno spuntino. Che bella compagnia, brigata lieta! Vi era fra mezzo a loro, anche un poeta!

Ed il poeta disse ad un passante : -L'indirizzo mi dia di un giacimento d'oro, ma che non sia troppo distante !x Gli fu risposto con beffardo, accento

-Da cercatori è giá il paese invaso.

Provi a scavar, ma se lo trova è un caso.»
-Scavare? maneggiar zappa e piccone? Incallírmi le man?-Non son cretino. lo venní in quésta aurifera' regione il milionario a far, non il facchino. Se devo lavorar, prendo la via e torno difilato a casa mia!-

E gli altri, intanto avevan combinato con dei fili di ferro, con del legno una specie di staccio, lavorato

con molta maestria, ma poco ingegno.

Fatto il lavor, si misero alla prova;

la giostra non andò, né fecero una nuova.

Ma questa ebbe lo stesso risultato.

Stanca allora si sciolse la congrega

e per non farsi il sangue avivelenato;

lasciaron tutto e chiusero bottega.

Un saluto a Marianna ed al prezioso monte,

e presèro il diretto per Bello Horizonte.

GIULIO BONCOMPAGNI

Nada pudemos encontrar sobre outros três poemas publicados no La Squilla, em uma mesma edição datada de 24/07/1927. "L'inno di....Frola" é assinado por "Uno che frolla nel manico"; "Il solito" e "Le ultime cartuccie" não são assinados. São reproduzidos abaixo para efeito de registro.

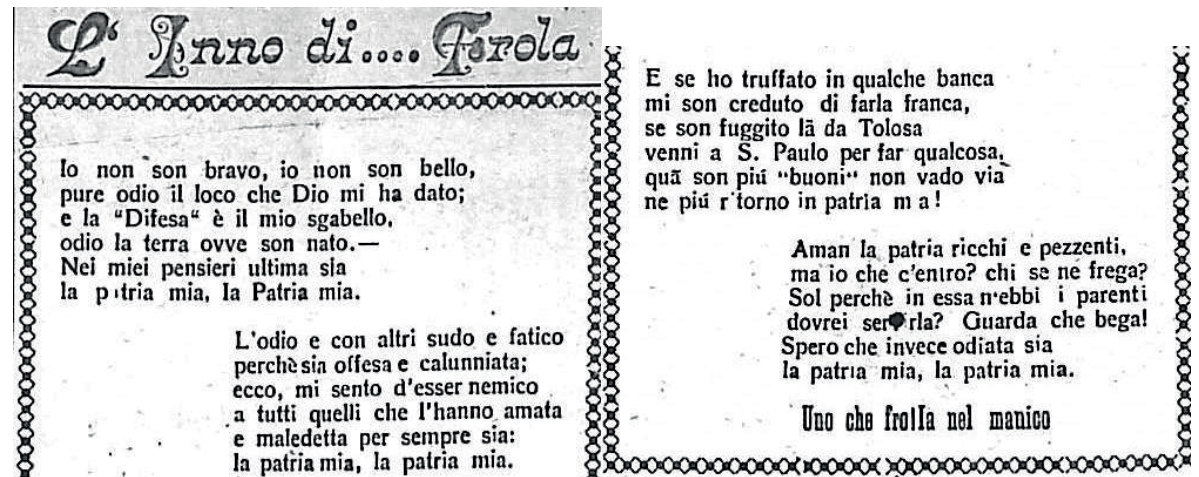




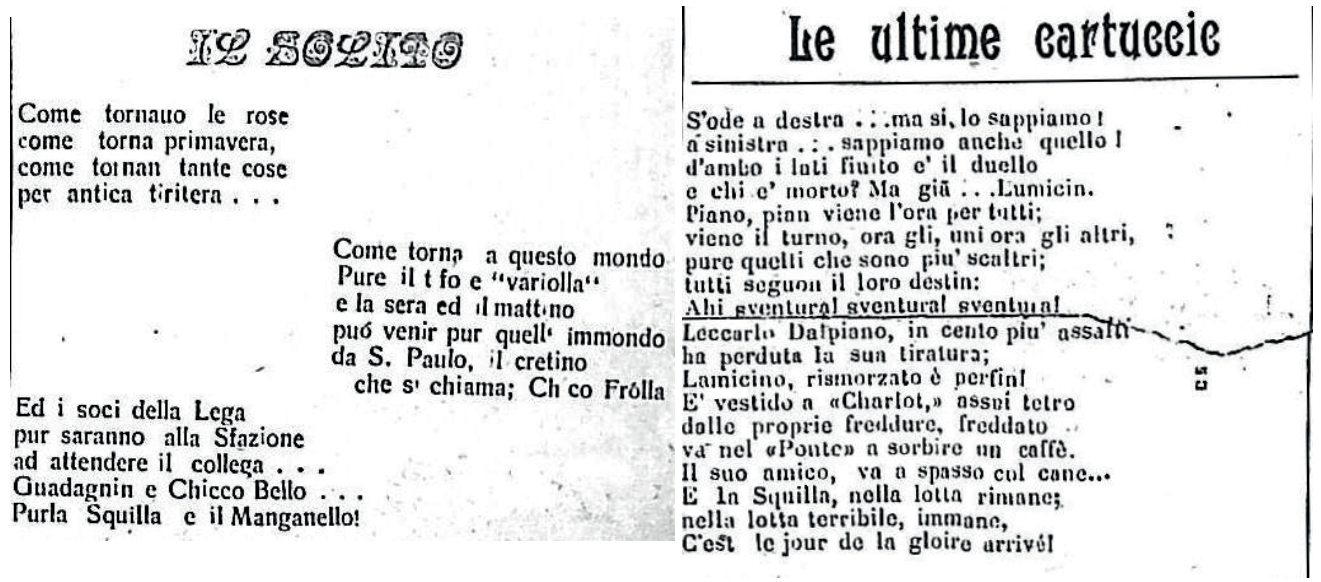

Além dos poemas acima mencionados, escritos em italiano, foram encontradas também composições poéticas produzidas em língua portuguesa - afinal, muitos dos periódicos voltados para a colônia italiana em Belo Horizonte publicavam conteúdo seja em italiano, seja em português. Na edição do Araldo Italiano de 31/07/1923, f.1, foi publicado o soneto "Oferenda", de autoria de Batista Santiago ${ }^{20}$, poeta do cenário literário belo-horizontino e revisor da Imprensa Oficial (MALARD, 2005). O mesmo Araldo Italiano também publicou, em 25/11/1923, f.2, o poema “Ao pequeno Vicente Tropia", assinado por Mario de Lima ${ }^{21}$. O poema está inserido em uma notícia sobre uma apresentação musical de Vicente Tropia, filho de pai italiano com mãe brasileira, então com apenas dez anos de idade. É interessante observar que Vicente de Oliveira Tropia - ou Vincenzo di Oliveira Tropia, na forma italianizada escrita no Araldo Italiano - posteriormente se tornaria um importante violinista da música brasileira. Já o periódico de orientação fascista Italia Nuova publicou, na mesma página de uma única edição (29/08/1928, f.2), três poemas em português homenageando o célebre aviador italiano Carlo del Prete, falecido alguns dias antes no Rio de Janeiro em decorrência de um acidente aéreo: "À memória de Carlos del Prete", assinado pelo pseudônimo "Um brasileiro"; "Carlos del Prete", assinado por Humberto Ramos; e "Último adeus ao aviador Del Prete", assinado por Ribeiro do Valle. Todas essas composições poéticas produzidas em língua portuguesa não foram reproduzidas aqui por restrição de espaço, mas podem ser consultadas diretamente na Coleção Linhares.

20 No jornal, o nome do poeta está grafado como Baptista Santiago e o título do soneto como Offerenda. 21 Acreditamos que este seja Mário de Lima (1886-1936): poeta parnasiano, ensaísta, jurista e professor universitário mineiro. 


\section{Considerações finais}

Muitos periódicos de imprensa belo-horizontinos publicados entre 1895 e 1954 se preservaram graças à Coleção Linhares, um rico e relevante acervo para o estudo da história da capital mineira. Uma parte dessa coleção é composta por periódicos elaborados por e para a comunidade de imigrantes italianos, que constituíam uma parcela considerável da população da cidade nas primeiras décadas do século XX. Não por acaso, Cavalieri (2011) lista treze jornais e revistas voltados para a colônia italiana em Belo Horizonte disponíveis na Coleção Linhares, sendo o mais antigo datado do ano de 1900 e o mais recente de 1937.

Neste trabalho, esses periódicos foram examinados a fim de que fossem compiladas, documentadas e brevemente analisadas composições poéticas neles publicadas. Foi possível identificar reproduções de poemas de autores conhecidos da literatura italiana e sem nenhuma relação com a colônia italiana belo-horizontina, mas também uma série de composições produzidas por membros da comunidade de imigrantes italianos no estado. Nota-se como esses espaços criativos permitiram a expressão artística dos integrantes da colônia, muitas vezes vinculando-a a eventos e acontecimentos de interesse da comunidade imigrante. Espera-se que este trabalho estimule futuras análises mais aprofundadas da literatura imigrante italiana em Minas Gerais, inclusive dos próprios poemas apresentados aqui.

Conforme o entendimento de Frosi e Raso (2011, p. 320), “é insuficientemente explorada a influência cultural italiana em Minas Gerais, onde a penetração numérica de italianos é menor somente do que aquela do Estado de São Paulo". Ao tornar pública a atividade literária e poética, geralmente amadora, dos imigrantes italianos que constituíram a capital do estado, pretende-se aqui atenuar essa lacuna, contribuindo assim para a divulgação de manifestações artísticas de comunidades de imigrantes em Minas Gerais e para uma melhor compreensão das dinâmicas sociais que as envolviam. 


\section{Referências}

ALMEIDA, Christobaldo Motta de. Pedro Pezzuti: é o patrono da Cadeira 70. http://www. acadmedmg.org.br/ocupante/pedro-pezzuti/ Acesso: 31/072019.

CAVALIERI, Daniel Gonçalves. Os imigrantes italianos e os ítalo-descendentes em Belo Horizonte: identidade e sociabilidade (1897-1942). 2011. 130 f. Dissertação (Mestrado em História) - Universidade Federal de Ouro Preto, Mariana, 2011.

COSTA, Geralda Nelma. Imprensa italiana em terra estrangeira: vozes sociais em ação (Belo Horizonte 1900-1920). 2005. 136 f. Dissertação (Mestrado em Comunicação Social) - Universidade Federal de Minas Gerais, Belo Horizonte, 2005.

. Imprensa italiana em Belo Horizonte (1900-1920): espaço virtual de encontros cotidianos. In $9^{\circ}$ ENCONTRO NACIONAL DE HISTÓRIA DA MÍDIA, 2013, Ouro Preto. Anais... [S.1.]: Associação Brasileira de Pesquisadores de História da Mídia, 2013.

CUNHA, Evandro L.T.P. Efeitos do contato linguístico na imprensa imigrante italiana de Belo Horizonte (1916-1919). In Cadernos do CNLF. No prelo.

DE LUCA, João Bosco Assis. Tolentino Miraglia (1890-1958), médico e poeta. In Revista da Associação Paulista de Medicina - Suplemento Cultural, n. 195, p. 4-5, set./out. 2008.

DOS PASSOS, Daniela Oliveira Ramos. Instituições sociais e a possível resolução do problema da ação coletiva: um estudo das associações trabalhistas de Belo Horizonte no início do século XX. In Teoria e Sociedade, n. 22.2, p. 187-217, jul./dez. 2014.

FILGUEIRAS, Zuleide Ferreira. A presença italiana em nomes de ruas de Belo Horizonte: passado e presente. 2011. 348 f. Dissertação (Mestrado em Estudos Linguísticos) - Universidade Federal de Minas Gerais, Belo Horizonte, 2011.

FROSI, Vitalina Maria; RASO, Tommaso. O italiano no Brasil: um caso de contato linguístico e cultural. In MELLO, Heliana; ALTENHOFEN, Cléo V.; RASO, Tommaso (org.) Os contatos linguísticos no Brasil. Belo Horizonte: Editora UFMG, 2011, p. 317-347.

LINHARES, Joaquim Nabuco. Itinerário da imprensa de Belo Horizonte: 1895-1954 / Joaquim Nabuco Linhares; estudo crítico e nota biográfica de Maria Céres Pimenta S. Castro. Belo Horizonte: Fundação João Pinheiro, Centro de Estudos Históricos e Culturais, 1995.

LOTT, Wanessa Pires. Cenas festivas da/na cidade de Belo Horizonte. 2009. 122 f. Dissertação (Mestrado em Antropologia) - Universidade Federal de Minas Gerais, Belo Horizonte, 2009.

MALARD, Letícia. No vasto mundo de Drummond. Belo Horizonte: Editora UFMG, 2005.

MIRAGLIA, Tolentino. Piccola antologia poetica brasiliana: versioni. São Paulo: Livraria Nobel, 1955.

MOREIRA DOS SANTOS, Vilma; SILVA DOS SANTOS, Silvana Aparecida; DOS SANTOS, Luiz Henrique. A Coleção Linhares em meio digital. In Varia Historia, v. 27, n. 46, p. 735-750, jul./dez. 2011.

SOUZA NETO, Georgino N. de; SILVA, Silvio Ricardo da. O advento do lazer em Belo Horizonte ou das "festas e diversões": um estudo dos hábitos de divertimento na 'cidade moderna' a partir do Minas Geraes. In Licere, v. 12, n. 2, jun. 2009.

TAVARES, Hênio. Teoria literária.4. ed. Belo Horizonte: Ed. Bernardo Álvares, 1969.

Recebido em: 19/10/2020

Aprovado em: 22/12/2020 